\title{
Penetrating cardiac trauma mimicking congenital sinus Valsalva aneurysm rupture: A case report
}

\author{
Ahmet Barış Durukan¹(D, Ahmet Ünlü1(D, Ali Cevat Tanalp² \\ ${ }^{1}$ Department of Cardiovascular Surgery, Medical Park Uşak Hospital, Uşak, Turkey \\ ${ }^{2}$ Department of Cardiology, Medical Park Uşak Hospital, Uşak, Turkey \\ Received: February 08, 2018 Accepted: September 03, 2018 Published online: April 24, 2019
}

\begin{abstract}
Penetrating cardiac injuries are rare, but often fatal. They may present with different manifestations. A 30-year-old male patient was admitted with self-inflicted left parasternal stab wound in the second intercostal space. Computed tomography revealed pericardial and pleural effusion. Echocardiography and aortography showed severe aortic regurgitation and aorto-right ventricular communication mimicking a congenital sinus Valsalva aneurysm rupture. The patient was operated and aortic leaflet repair with a pericardial patch and closure of the communication on both aortic and right ventricular sides were performed. In conclusion, although such traumatic injuries are rare, they may be life-threatening and, therefore, requires prompt treatment.
\end{abstract}

Keywords: Congenital sinus; heart injuries; penetrating injuries; Valsalva aneurysm rupture.

Penetrating cardiac injuries are rare, but represent a high mortality in most cases. The injury is usually nonaccidental, predominantly sustained by males, and the mortality rate is about $60 \%$, which further increases where pericardial tamponade is absent. ${ }^{[1,2]}$ In a recent large series, $86 \%$ of injuries constituted single chamber injury, predominantly right ventricle $(46 \%)$ and left ventricle $(24 \%)$, whereas multi-chamber injuries were seen in $18 \%$ of cases. Patients typically manifest with signs of cardiac tamponade, cardiac arrest, or signs of extremis from exsanguination. ${ }^{[2]}$

Congenital sinus Valsalva aneurysms are rare abnormalities often presenting with rupture. In more than $80 \%$ of cases, the rupture originates from the right coronary sinus (RCS). Aorto-right ventricular connection is observed in $65 \%$ of cases. ${ }^{[3,4]}$

Herein, we report a case of aorto-right ventricular communication concomitant with aortic regurgitation due to self-inflicted stab wound injury.

\section{CASE REPORT}

A 30-year-old male patient was admitted to the cardiology department with chest pain. He had a selfinflicted left parasternal stab wound in the second intercostal space two days ago after heavy alcohol intake. He did not remember the type of knife used.
He was examined in a rural medical center and the skin wound was sutured. The patient reported no complaint subsequently. Echocardiography and aortography revealed aortic valve regurgitation due to a defect in the right coronary cusp (RCC) and aorto-right ventricular communication (Video 1). Pericardial and bilateral pleural effusion was noted on echocardiography and computed tomography (CT) scan (Figure 1a). He had no signs of tamponade or pathological findings, except for the sutured wound (Figure 1b).

He was scheduled for an urgent operation and a written informed consent was obtained. A median sternotomy was performed. Due to the possibility of aortic injury, right femoral artery was cannulated to initiate cardiopulmonary bypass (CPB) immediately following pericardiotomy. Hematoma and defibrinated blood were present in the pericardial space. A very little adventitial hematoma was located in the left lateral side of the aorta above the sinotubular

Corresponding author: Ahmet Barış Durukan, MD. Medical Park Uşak Hastanesi Kalp ve Damar Cerrahisi Bölümü, 64200 Uşak, Turkey.

Tel: +90 276 - 2272233 e-mail: barisdurukan@yahoo.com

\section{Citation:}

Durukan AB, Ünlü A, Tanalp AC. Penetrating cardiac trauma mimicking congenital sinus Valsalva aneurysm rupture: A case report . Cardiovasc Surg Int 2018;5(3):40-42. 
junction. The right atrium was cannulated and $\mathrm{CPB}$ was initiated. Transverse aortotomy was performed. There was a slit-like linear opening on RCS connected with right ventricular cavity (Figure 1c). There was also a $2 \times 1 \mathrm{~cm}$ defect in the RCC. Transverse right ventriculotomy was performed to visualize the opening of the defect and a slit-like linear opening was noted (Figure 1d).

The aortic side of the opening was sutured with two Teflon pledgeted sutures (Figure 1e) and the right ventricular side with the Teflon felt on both sides (Figure 1f). The defect in the RCC was repaired with a fresh pericardial patch. Aortotomy was closed and the patient was weaned from CPB. The postoperative course was uneventful and postoperative echocardiography revealed no aortic regurgitation or aorto-right ventricular communication. In the first year of follow-up, the patient is still stable with normal echocardiographic findings.

\section{DISCUSSION}

Penetrating cardiac injury is often fatal with a mortality rate over $60 \%$. Multi-chamber injuries constitute a lower percentage of cases with a predominant single right ventricle injury. ${ }^{[1,2]}$ The present case is unique, as it is a late admission and had no signs of hemodynamic compromise,

\section{(a)}

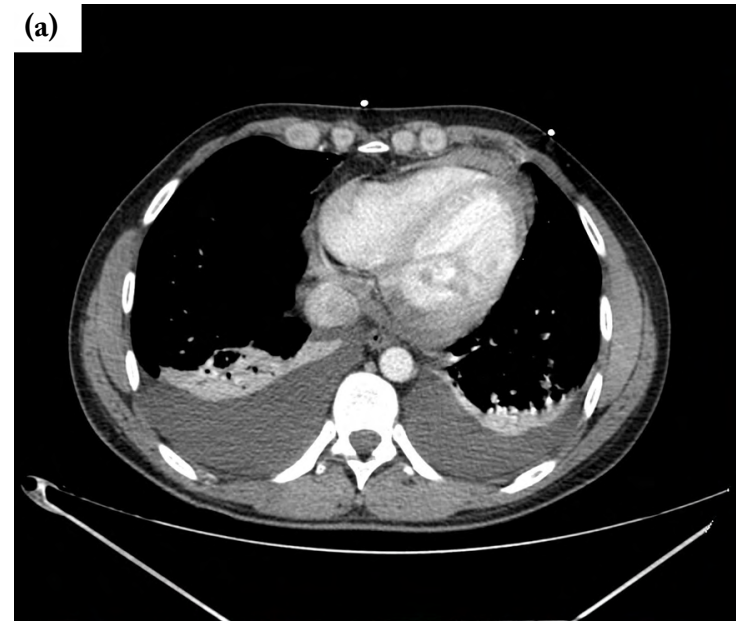

(b)
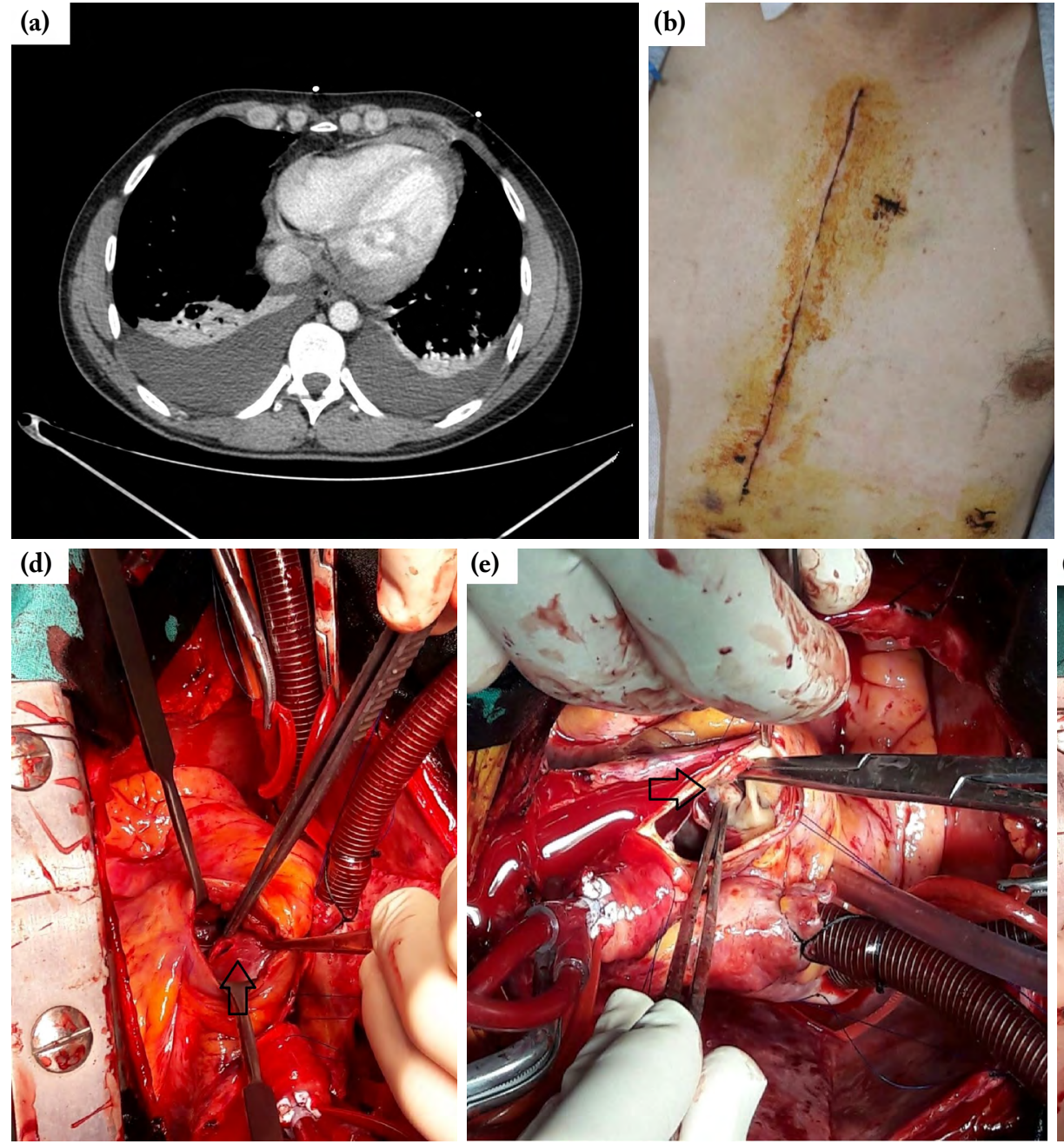

(c)
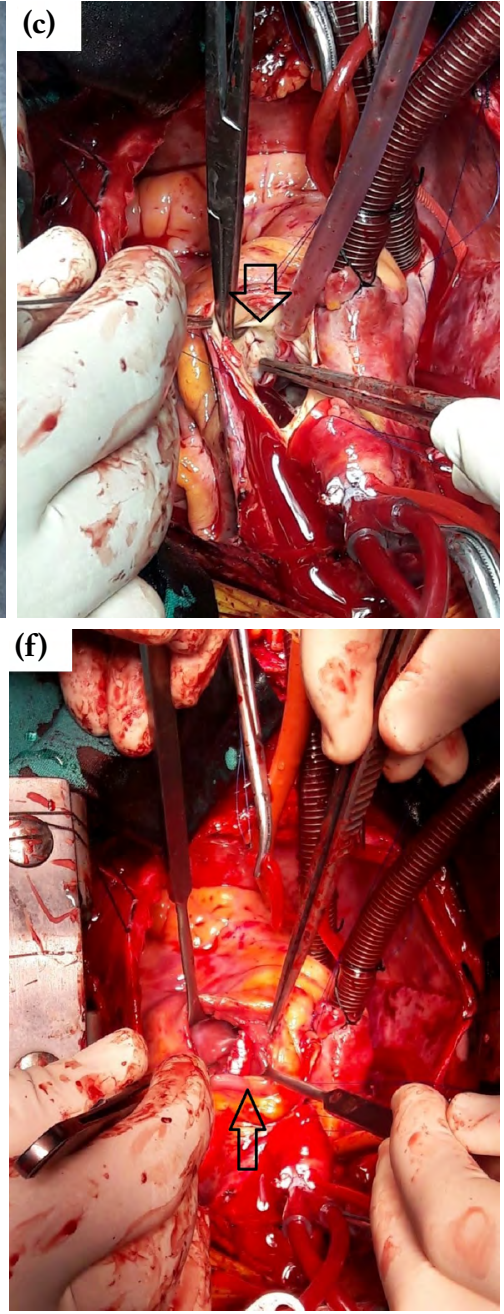

Figure 1. (a) Computed tomography scan showing pericardial and bilateral pleural effusion. (b) The stab wound injury in the second left parasternal intercostal space. (c) Aortic slit-like linear injury (arrow). (d) Right ventricular slit-like linear injury (arrow). (e) Aortic side of repair with two Teflon pledgeted sutures (arrow). (f) Right ventricular side of repair with over and over suture supported with Teflon felts on both sides (arrow). 
despite a great injury with an aorto-right ventricular communication.

Such an injury might have caused a great hemodynamic compromise due to signs of exsanguination or cardiac tamponade. However, our case had no complaints at the time of injury and was admitted two days later due to chest pain. Surprisingly, pericardial effusion was not much and did not cause tamponade within two days. There was a small adventitial hematoma in the left lateral side of the aorta, however, there was neither hemorrhage from the aorta nor a visible aortic injury site. In this case, the injury mimicked a ruptured congenital sinus Valsalva aneurysm, although it was truly a multichamber injury involving the ascending aorta. The $\mathrm{RCC}$ was also injured and repaired with a pericardial patch.

There is a limited number of reports in the literature showing similar pathologies. ${ }^{[5,6]}$ Such an injury may be fatal at the time of injury, and it is quite surprising that our patient survived. In addition, he did not remember the type of knife used, although we suspected a skewer-like thin and long tool.

In conclusion, penetrating cardiac injuries may represent as unique pathologies and require major interventions. If possible, repair should be preferred, if valvular pathologies exist.

\section{Declaration of conflicting interests}

The authors declared no conflicts of interest with respect to the authorship and/or publication of this article.

\section{Funding}

The authors received no financial support for the research and/or authorship of this article.

\section{REFERENCES}

1. Connelly TM, Kolcow W, Veerasingam D, DaCosta M. A severe penetrating cardiac injury in the absence of cardiac tamponade. Interact Cardiovasc Thorac Surg 2017;24:28687.

2. Morse BC, Mina MJ, Carr JS, Jhunjhunwala R, Dente CJ, Zink JU, et al. Penetrating cardiac injuries: A 36-year perspective at an urban, Level I trauma center. J Trauma Acute Care Surg 2016;81:623-31.

3. Abralov K, Alimov A. Short-term results of sinus of valsalva aneurysm repair. World J Pediatr Congenit Heart Surg 2017;8:13-7.

4. Yadav A, Mathur R, Devgarha S, Abraham V, Sisoida A. Surgery for ruptured sinus of Valsalvaaneursym: Fiveyear experience with 19 patients. Turk Gogus Kalp Dama 2014;22:729-33.

5. Esfahanizadeh J, Abbasi Tashnizi M, Moeinipour AA, Sepehri Shamloo A. undetected aorto-rv fistula with aortic valve injury and delayed cardiac tamponade following a chest stab wound: a case report. Trauma Mon 2013;18:95-7.

6. Kaya A, Dekkers P, Loforte A, Jaarsma W, Morshuis WJ. Traumatic aorto-right ventricular fistula with aortic insufficiency. Ann Thorac Surg 2005;80:2362-4. 